\title{
CRISIS DEL AGUA EN EL NORTE DE CHILE. DERECHO Y CULTURA EN LOS ANDES. SOBRE LOS EFECTOS IRRACIONALES DEL DERECHO
}

\author{
WATER CRISIS IN THE NORTH OF CHILE. LAW AND CULTURE \\ IN THE ANDES. ON THE IRRATIONAL EFFECTS OF LAW
}

\author{
Karenn Alejandra Díaz Campos*
}

\begin{abstract}
En el artículo se realiza una investigación sobre la relación que el Estado de Chile mantiene con los pueblos originarios andinos, sobre el uso compartido del agua, desde una perspectiva jurídica y social. Así las cosas, considero importante establecer que, a nuestro juicio, no se han implementado verdaderas políticas públicas que apunten a responder a las necesidades de reconocimiento de la posesión ancestral de las aguas de los pueblos indígenas. Dicha postura se sostiene en los siguientes puntos: 1) la Constitución Política de la República de Chile no contiene un verdadero reconocimiento de su carácter intercultural, lo que en la práctica facilita que en la instauración de políticas públicas se transgreda el derecho de la identidad cultural de los pueblos indígenas en Chile. 2) En América Latina, las "culturas de aguas" forman parte del uso y manejo racional del agua y en Chile no se tiene una verdadera claridad conceptual sobre el alcance de estos usos consuetudinarios 3) El uso consuetudinario del agua por los pueblos indígenas del desierto de Atacama ha sido reconocido como un ejercicio de derecho propio de pueblos indígenas en Chile, tanto a nivel de la doctrina como la jurisprudencia nacional e internacional.
\end{abstract}

Palabras claves: Derecho al agua en Chile, Convenio No 169 de la OIT, Pueblos Indígenas.

This article is an investigation that contributes to the study of my discipline on the delimitation of the relationship that the State of Chile has maintained with the Andean native peoples, on the shared use of water, from a legal and social perspective. Thus, I consider it important to establish that, in our opinion, true public policies that aim to respond to the needs for recognition of the ancestral possession of the waters of indigenous peoples have not been implemented. This position is supported by the following points: 1) the Political Constitution of the Republic of Chile does not contain a true recognition of its intercultural character, which in practice facilitates that in the establishment of public policies the right of cultural identity of indigenous peoples in Chile is violated. 2) In Latin America, "water cultures" are part of the rational use and management of water and in Chile there is no real conceptual clarity about the scope of these customary uses. 3) The customary use of water by the indigenous peoples of the the Atacama Desert has been recognized as an exercise of the right of indigenous peoples in Chile, by both national and international doctrine and jurisprudence.

Key words: Right to water in Chile, ILO Convention $N^{o} 169$, Indigenous Peoples.

\section{Introducción}

En este trabajo se presentan algunos conceptos correspondientes a la cosmovisión indígena andina del desierto de Atacama que, buscan hacer una necesaria defensa de la "cultura del agua" de los pueblos indígenas, como manifestación del derecho consuetudinario indígena. Presentando esta como parte del necesario reconocimiento intercultural que debe realizar un Estado nacional de América Latina que, se denomina social de derecho. En esta línea se comprende que, en Chile coexisten varios sistemas jurídicos, el impuesto por el Estado nacional y el propio indígena, esto a su vez, podría implicar el derecho de los mismos indígenas a auto determinar su uso del agua, y ello debe manifestarse por medio del establecimiento de políticas públicas de cuidado de esta en Chile.

En la base de ello nos enfrentamos a un problema mayor que, dice relación con los efectos irracionales del derecho en las comunidades ancestrales, sobre todo de un derecho hegemónico que, en la práctica y en su ejecución no reconoce las reglas de control social derivadas de la costumbre indígena. Conocido es que, actualmente el derecho nacional reconoce la costumbre como fuente de derecho para los pueblos indígenas en el marco del Convenio $\mathrm{N}^{\mathrm{o}} 169$ de la Organización Internacional del Trabajo sobre pueblos indígenas y tribales, el que en su artículo 8 establece que,

\footnotetext{
* Universidad Arturo Prat, Facultad de Ciencias Jurídicas y Políticas. Línea de Investigación en Interculturalidad, Territorio, Aguas y Derecho Indígena. Iquique, Chile. Correo electrónico: karecamp@unap.cl
} 
al aplicar la legislación nacional a los pueblos interesados deberán tomarse en consideración sus costumbres o su derecho consuetudinario. Por su parte la Ley 19.253 que establece normas sobre protección, fomento y desarrollo de los indígenas establece en su artículo 54 un reconocimiento a la costumbre indígena y su aplicación en materia de justicia.

Sin embargo, este reconocimiento nacional e internacional y a nivel legal no se ha visto reflejado en la instauración de políticas públicas por parte del gobierno que obedezcan a dichos principios. A fin de ejemplificar lo antes expuesto, este trabajo se centrará en el análisis del cierre de la cuenca hidrogeológica Pampa del Tamarugal y la afectación del pueblo indígena Aymara y Quechua. Esto nos deja ante lo que conocemos como un derecho vaciado de contenido, con sus consecuentes irracionales efectos. Para subsanar esto último se propone instalar un modelo jurídico intercultural que, permita asegurar el cumplimiento de los deberes internacionales del Estado de Chile, así como que se configure un bloque jurídico de protección a nuestros pueblos indígenas.

Se considera entonces que, el cierre de la cuenca hidrogeológica del Tamarugal es una manifestación de los efectos irracionales del derecho hegemónico, especialmente en lo que refiere al establecimiento de políticas públicas con respecto al uso del agua en Chile. Teniendo presente que, como se desarrollará en este trabajo, la situación de inequidad en la distribución de los derechos de agua en el norte de Chile es incluso anterior al cierre de la cuenca Pampa del Tamarugal y que, ello es fruto del establecimiento de las antes mencionadas políticas públicas.

\section{Antecedentes del cierre de la cuenca hidrogeológica Pampa del Tamarugal y de la distribución inequitativa del agua en el norte de Chile}

Es importante en esta parte entregar algunos datos de la cuenca hidrogeológica Pampa del Tamarugal, a fin de entender la experiencia práctica de la aplicación de medidas y políticas de la administración pública del Estado de Chile en el desierto de Atacama. La cuenca hidrogeológica del acuífero Pampa del Tamarugal, abarca las comunas de Huara, Pozo Almonte y Pica, pertenecientes a la región de Tarapacá, se presenta desde la quebrada de Tana por el norte hasta el río Loa por el sur. Según indica el Centro de Estudios de Desarrollo y la Corporación Nacional de Desarrollo Indígena (2012) la cuenca se caracteriza por la depositación de sedimentos finos arrastrados por los caudales esporádicos que bajan desde la precordillera. Dentro de esta cuenca y según registros de la misma Dirección General de Aguas y la subdirección norte de la Corporación Nacional de Desarrollo Indígena (2017), se encuentran 602 personas que detentan la calidad de indígenas, incluyendo a siete asociaciones indígenas y dos comunidades indígenas. Con respecto al registro conservatorio chileno de estos territorios, la ocupación "de hecho" de espacios territoriales por propietarios u ocupantes de tierras peruanos o extranjeros fue cuestionada por la aplicación de legislación chilena, lo que requirió su reinscripción en los Conservadores de Bienes Raíces de Chile, lo que en muchas veces no sucedió, por lo que, por aplicación de dominio del Estado, fueron reputadas a dominio fiscal (Ruz, R. 2005). Es en este escenario que, el Estado de Chile en el año 2009 y a través de la resolución administrativa número 245 de la Dirección General de Aguas, declaró una restricción para nuevas extracciones de aguas subterráneas en la Pampa del Tamarugal. El 01 de junio del año 2010 la antedicha resolución fue publicada en el Diario Oficial y desde dicha fecha, no se tramitan nuevas solicitudes de aprovechamiento de aguas subterráneas, ni siquiera de carácter provisorio, incluyéndose las aguas que ancestralmente ocupan los pueblos indígenas de dicha cuenca en el desierto de Atacama. Es así como esta aplicación irrestricta de una resolución administrativa a las comunidades indígenas y en opinión de la Corporación Nacional Desarrollo Indígena (2017) impide a los agricultores y ganaderos indígenas contar con un título de dominio, sobre derechos de agua que ancestralmente poseían.

La geografía y ubicación de la cuenca Pampa del Tamarugal está constituida por la Cordillera de los Andes, Pampa del Tamarugal y Cordillera de la Costa. Abarca un área hidrogeológicamente cerrada de 8.300 kilómetros cuadrados, que limita al este con la Cordillera de los Andes, al oeste con la Cordillera de la Costa, al norte con la cuenca hidrográfica de Quebrada de Aroma y al sur con Cerro Gordo (Dirección General de Aguas, 2014). Las tierras Aymara y Quechua que se ven afectadas por la resolución número 245 , a 
las que nos referimos, fueron definidas en el año 1998 por un catastro que levantó el Ministerio de Bienes Nacionales, de acuerdo a la ejecución de un plan de saneamiento de las tierras Aymara y atacameñas para la I y II región mandatado por la Ley 19.253. Este catastro arrojó la existencia de 190 propiedades, 30 de propiedad fiscal y 160 de propiedad Aymara. En la comuna de Colchane, provincia de Iquique, el $70 \%$, y en la comuna de Pica, el 10\% de la superficie comunal. A ello debemos sumar la propiedad agrícola Aymara que se ha constituido fundamentalmente en las quebradas altas y bajas que nacen del altiplano y bajan hasta la costa o pampa intermedia en los oasis de la Pampa del Tamarugal (Aylwin, J; MezaLopehandia, M. y Yáñez, N. 2013).

El cierre de la cuenca hidrogeológica Pampa del Tamarugal afecta a un número aproximado de 769 usuarios, según registro de la Dirección General de Aguas. Universo de usuarios de los cuales 602 personas detentan la calidad de indígenas, incluyendo siete asociaciones indígenas y dos comunidades indígenas Aymara, en contraposición a los demás usuarios que solo corresponden a 167 personas naturales y jurídicas (Conadi, 2017). Este cierre afecta a las asociaciones y comunidades indígenas Aymara y Quechua que ocupan los territorios de la quebrada del Tamarugal, a saber Huara, Pozo Almonte y Pica, incluyendo en estos, sectores como Bajo Soga, La Tirana, La Huayca, Valle de Quisma, entre otros (Corte de Apelaciones de Iquique, 2017).

La declaración de esta área de restricción es una medida de carácter preventivo que se realiza en base a estudios que demuestran que existe riesgo de grave disminución de un determinado acuífero y no necesariamente frente a la constatación de un deterioro real en la actualidad, según lo declara la misma Dirección General de Aguas (2009) en su resolución número 245. Como ya hemos mencionado, la cuenca hidrogeológica Pampa del Tamarugal fue declarada como área de restricción para nuevas extracciones de aguas subterráneas en el año 2009 por la resolución administrativa número 245 de la Dirección General de Aguas. Esta resolución determinó además, la constitución de una comunidad de aguas subterráneas para dicho sector hidrogeológico, compuesto por todos los usuarios de aguas subterráneas (Dirección General de Aguas, 2009), sin distinguir entre usuarios indígenas y no indígenas.
Entre las comunidades indígenas afectadas por el cierre de la cuenca encontramos la Comunidad indígena del Pueblo de Colchane que tiene inscrito a su nombre el lote $\mathrm{N}^{\circ} 3$ ubicado en el Pueblo de Zapiga, en la comuna de Huara, la que a su vez se encuentra inscrita en el registro público de Tierras Indígenas de la Corporación Nacional de Desarrollo Indígena. La comunidad de Colchane además, detenta derechos de aprovechamiento de aguas subterráneas por un caudal de 2 litros por segundo, de ejercicio permanente y continuo, inscrito a fojas $391 \mathrm{~N}^{\circ} 131$ del año 2007, y de un caudal de un litro por segundo de ejercicio permanente y continuo, inscrito a fojas $395 \mathrm{~N}^{\circ} 132$ del año 2007 (Conadi, 2017).

En la proporción actual de titulares de los derechos de aprovechamiento de aguas del sector de la cuenca hidrogeológica Pampa del Tamarugal en el desierto de Atacama, los indígenas quedan en franca desventaja puesto que, los derechos de agua del sector pertenecen en un $11 \%$ compuesto mayoritariamente por personas y organizaciones indígenas, un total 59\% entre la Empresa Concesionaria de Servicios Sanitarios S.A. y mineras metálicas y no metálicas. Lo anterior de un total de aproximadamente 769 usuarios con derechos de aprovechamiento de aguas, según inscripción de los mismos, de los cuales la mayoría detenta la calidad de indígenas. (Conadi, 2017). De esta distribución puede concluirse que, incluso antes de la dictación de la resolución $\mathrm{N}^{\circ} 245$, antes mencionada, los pueblos indígenas veían afectado su acceso al agua. Específicamente desde la entrada en vigencia del Código de Aguas de 1981, donde se otorga a los particulares un derecho real de aprovechamiento de las aguas que pasa a ser propiedad de su titular. De la aplicación de esta normativa y en opinión de Núñez, comienza un progresivo desecamiento de vegas y bofedales de los Aymara (Núñez, 2002, en Yáñez, 2011), lo que se vio agravado durante el Gobierno militar por las presiones del mercado hacia la enajenación de los recursos productivos indígenas (Yáñez, 2011).

A esta ya inequitativa distribución del agua en el norte de Chile se suma la aplicación irrestricta de la resolución administrativa número 245 a las comunidades indígenas andinas y, en opinión de la Corporación Nacional Desarrollo Indígena (2017), implica el cierre de la cuenca acuífera hidrogeológica del Tamarugal. Dicha resolución impide a los agricultores y ganaderos 
indígenas contar con un título de dominio, sobre derechos de agua que ancestralmente poseían. Es por tanto, de interés de este trabajo ahondar en cómo esta resolución administrativa viene a desconocer la costumbre jurídica y cosmovisión indígena respecto a los usos ancestrales del agua. Tal como plantean Pelfini y Mena (2017) la política pública que introduce nuevos estándares de gobernanza, transparencia y participación ciudadana, en el caso de la nueva institucionalidad ambiental, pero no contribuye a la formación de ciudadanía y agenda pública en torno a modelos de desarrollo y de uso compartido de recursos naturales.

\section{Marco jurídico que regula el agua en Chile}

De forma previa entonces debemos, brevemente hablar del marco jurídico que regula el agua en Chile. Desde el año 1979, con el Decreto Ley $\mathrm{N}^{\circ} 2.603$, el agua se consideró como un recurso susceptible de apropiación por privados que, se entrega principalmente al mercado, sistema consagrado de esa forma por la Constitución de 1980 y el Código de Aguas de 1981 (Guerra, 2016). A su vez el marco normativo chileno reconoce una especial protección de las aguas de las comunidades indígenas Aymara, Atacameña, Quechua y Coya del norte de Chile, la Ley 20.117 del año 2006 hace extensivos estos derechos a los diaguitas (Yáñez, 2011).

El artículo 64 de la Ley 19.253 reconoce a las comunidades indígenas del norte de Chile el derecho de propiedad sobre las aguas, basado en sus derechos ancestrales de uso, prohibiendo la constitución de nuevos derechos de aguas sobre los acuíferos que surten a las aguas de propiedad de varias comunidades indígenas, si es que no se garantiza, en forma previa el normal establecimiento de aguas a las comunidades afectadas. (Ley 19.253, 1993). Así también, el mismo Código de Aguas de Chile establece un sistema de regularización de títulos de los derechos de aprovechamiento de aguas de los usuarios que, a la entrada en vigencia del Código de Aguas hubieren cumplido cinco años de uso ininterrumpido de dichas aguas. Por último, se encuentra la protección y reconocimiento a los derechos de los pueblos indígenas a los recursos naturales existentes en sus tierras que establece el Convenio $\mathrm{N}^{\circ} 169$ de la Organización Internacional del Trabajo.
Pareciera entonces, en lo que respecta al reconocimiento de usos ancestrales del agua derivados de la costumbre indígena, que el Estado de Chile ha reconocido el derecho preferente de constitución de las aguas en favor de las comunidades indígenas del norte de Chile, fundado en sus derechos ancestrales (Yáñez y Molina, 2011). Lo anterior sería en la teoría, la evidencia empírica, demostrada en la instauración de determinadas políticas de explotación de los recursos naturales del Estado de Chile, así como de conservación del recurso hídrico en el norte grande de Chile; de que el derecho ancestral al agua de los pueblos indígenas no ha sido debidamente considerado (Yáñez y Molina, 2011). Independiente de que el Estado exige que las aguas en Chile solo pueden tomarse con su autorización o concesión, es reconocido que en el norte de Chile y de parte de los pueblos indígenas andinos, las aguas se han utilizado siempre, sin previa concesión. Esto, en opinión de Vergara, no implica que tales usos sean ilegítimos, lo que es reconocido por nuestra legislación y posibilita la regularización de los usos que se han realizado de las aguas por las comunidades indígenas (Vergara, 1998).

La instauración de políticas públicas de mantención del agua en el desierto de Atacama y el cierre de la cuenca hidrogeológica Pampa del Tamarugal en dicho desierto, demuestran que la autoridad pública regula desconociendo su propia normativa interna, así como la costumbre jurídica y cosmovisión indígena respecto a los usos ancestrales del agua. En mi opinión, el establecimiento de políticas de resguardo de caudales del agua a comunidades indígenas, como es el caso en estudio, manifiesta un conjunto de efectos irracionales del derecho, donde se llega a afectar directamente el principio de seguridad jurídica del sistema de regularización de títulos de los derechos de aprovechamiento de aguas de dichas comunidades indígenas de Atacama. Se hace evidente que el ejecutivo, manifiesta un desentendimiento de los usos ancestrales del agua por parte de los pueblos andinos en el desierto de Atacama e incluso de la propia normativa nacional. No estamos ante una mera expectativa de reconocimiento, sino del deber de reconocimiento de derechos de propiedad ancestral que obedecen a necesidades culturales, económicas y sociales de los pueblos, cuya existencia es anterior a la configuración del Estado de Chile. 


\section{Del derecho de uso consuetudinario del agua del pueblo Aymara y Quechua en el desierto de Atacama}

De acuerdo a lo que expone Huenchumilla (2017) citando los datos del censo del año 2017, realizado por el Instituto Nacional de Estadísticas 2.185.792 personas declaran pertenecer a algún pueblo indígena, esto equivale a un $12,4 \%$ de la población del país. De estos, 156.754 corresponden al pueblo Aymara y 33.369 al Quechua. La realidad de los pueblos indígenas en Chile es compleja, tanto en lo socioeconómico como en lo jurídico-político, los distintos Gobiernos de la transición a la democracia han desarrollado políticas de desarrollo indígena que, no han logrado acabar con la exclusión, la pobreza, la marginación social, la discriminación y la represión que viven muchos indígenas. $\mathrm{Al}$ respecto cito a Delia Condori, quien en el libro "Nueva Constitución y Pueblos indígenas expresa lo siguiente:

Chile, un país de contrastes. Mientras en todos lados se habla de crecimiento económico y de lo atractivo que es este país -en la región-, para inversionistas extranjeros, turistas y potenciales residentes; existe una población sobreviviente identificada como "pueblos originarios", que lucha cada día, por lo que le fue arrebatado, por su reconocimiento, por la invasión a sus tierras, por la pérdida paulatina de los elementos que conforman sus formas de vida y sanación, por la alteración al mediambiente en que ha vivido por siglos; los pueblos no crecen, no son atractivos; cada día que pasa se pierde más: idioma, costumbres, prácticas ancestrales, son solo algunos aspectos. Somos el "pariente pobre" de este país en vías de desarrollo (Condori, D. en Namancura, D., Pinto, J. 2016:143).

Referente a la situación de precariedad en el acceso del agua de los pueblos indígenas andinos en Chile, el Banco Mundial en el año 2011 emitió un informe titulado Chile: Diágnostico de la gestión de los recursos hídricos. Este informe da cuenta de que, la zona de mayor crisis hídrica en el país es la que corresponde a las cuencas andinas del norte, donde se asienta el territorio
Aymara, Atacameño o Lickanantai, Quechua, Coya y Diaguita, producto principalmente de la escasez de agua, el impacto del cambio climático, la contaminación y la sobreexplotación de los recursos hídricos (Banco Mundial, 2011, citado por Yañez N., 2013).

Y sobre este punto es relevante justificar lo expresado. Salgado y Gomiz nos indican que a nivel internacional es conocido que los pueblos indígenas y su propiedad ameritan una especial protección constitucional e internacional, sobre todo cuando hablamos de la posibilidad real que se tiene de acceder a los recursos naturales, y que tienen como finalidad la protección de la vida e identidad colectivas. El Convenio 169 de la OIT es un tratado internacional de derechos humanos, sobre lo que importa entender que, una vez ratificados y vigentes obligan a todos los órganos del Estado. Esta obligación proviene de lo dispuesto en el artículo 5 inciso $2^{\circ}$ de la Constitución, donde se establece que el ejercicio de la soberanía reconoce como limitación el respeto a los derechos esenciales que emanan de la naturaleza humana. Es deber de los órganos del Estado respetar y promover tales derechos, garantizados por esta Constitución, así como por los tratados internacionales ratificados por Chile y que se encuentren vigentes. En opinión de Mata si se toma en serio la disposición del inciso segundo del artículo 5 de la Constitución, los órganos del Estado se encuentran obligados por este tipo de tratados y, por lo tanto, están obligados a aplicarlos, por lo que no tienen potestad de suspenderlos (Mata, M. En Contesse, J., 2012). Y es precisamente en ello donde nos encontramos ante el incumplimiento de las obligaciones establecidos en el Convenio 169 de la OIT en el caso en cuestión, como en el tratamiento general del territorio de los pueblos andinos del norte de Chile. En la causa rol No534/2017 de la Corte de Apelaciones de Iquique, caratulada "Challapa con Dirección General de Aguas" se emitió un informe por parte de la Dirección General de Aguas de Chile con el ORD.DL N ${ }^{\circ} 78$, de parte del abogado jefe de la División legal de dicha dirección donde al referirse a las garantías eventualmente vulneradas por falta de consulta indígena, alega:

En efecto, entender que a los recurrentes se les debe conceder derechos de aprovechamiento de aguas subterráneas en un sector hidrogeológico restringido, en desmedro de las personas naturales y jurídicas que no son consideradas como 
indígenas o comunidades indígenas al tenor de lo presupuestado en la Ley 19.253, de 1993, que Establece Normas Sobre Protección Fomento y Desarrollo de los Indígenas, y crea la Corporación Nacional de Desarrollo Indígena, importaría una verdadera afectación a la garantía del artículo 19 $\mathrm{N}^{\circ} 2$ analizada anteriormente, por cuanto sería una discriminación arbitraria que afectaría a todas las personas que no cumplen los requisitos del artículo 2 y 9 de la citada ley (García, J., 2017:2).

Es decir, en la práctica no se respeta e incluso se desconoce el Convenio $\mathrm{N}^{\circ} 169$ de la OIT, el que su artículo 15 regula expresamente que los recursos de los pueblos interesados a los recursos naturales existentes en sus tierras deberán protegerse especialmente. Estos derechos comprenden el derecho de esos pueblos a participar en la utilización, administración y conservación de dichos recursos. De lo argumentado en el informe emitido por la Dirección General de Aguas, solo podría otorgarse derechos de aprovechamiento a las comunidades indígenas de las comunas de Huara, Pozo Almonte y Pica, si estos son abiertos para todos sujetos posibles no indígenas, incluyendo personas jurídicas, porque de otra forma se estaría discriminando arbitrariamente a estos últimos. De donde encontramos, además violentación al artículo 13 del Convenio que nos indica que al aplicar las disposiciones, sobre tierras indígenas, los Gobiernos deberán respetar la importancia especial que para las culturas y valores espirituales de los pueblos interesados reviste su relación con las tierras o territorios. Tampoco tiene en cuenta el artículo 14 del Convenio $\mathrm{N}^{\circ} 169$ de la OIT el que reconoce a los pueblos indígenas el derecho de propiedad y posesión sobre las tierras que tradicionalmente ocupan y reconoce que, en los casos apropiados, deberán tomarse medidas para salvaguardar el derecho de los pueblos interesados a utilizar tierras que no estén exclusivamente ocupados por ellos. Así también, el artículo 14 del Convenio en su númeral 2 y 3 establece que los Gobiernos deberán tomar medidas que sean necesarias para garantizar la protección efectiva de sus derechos de propiedad y posesión y el deber del Gobierno de instituirse procedimientos adecuados en el marco del sistema jurídico nacional para solucionar las reivindicaciones de tierras formuladas por los pueblos interesados.

Es así como, en opinión de Nancy Yáñez, se han excluido del marco normativo en el que se reflexiona de los pueblos indígenas en Chile los instrumentos generales de derechos humanos, ratificados y vigentes en el derecho chileno, como lo es la Convención Americana sobre Derechos Humanos, el Pacto Internacional de Derechos Civiles y Políticos y el Pacto Internacional de Derechos Económicos, Sociales y Culturales, que son fundamentales para el reconocimiento de los pueblos indígenas, y en particular al desarrollo con identidad en el ámbito de su derecho a los recursos naturales, incluídos en estos el agua (Yañez, N. en Contesse, J., 2012). Reflejando lo antes expuesto y en opinión de Maite de Cea y Claudio Fuentes (2017), un reconocimiento débil de los derechos de pueblos indígenas en Chile.

Lo interesante de lo expuesto es el fundamento de la exclusión de los pueblos indígenas en la construcción de políticas públicas en Chile e instaura desde la negativa de reconocimiento en la misma Constitución Política de la República. Tal como indica Maite de Cea y Claudio Fuentes la propuesta de reconocimiento constitucional de los pueblos indígenas en Chile ha encontrado el rechazo de los partidos de derecha que, hasta el 2013 mantenían fuerte control del parlamento (De Cea y Fuentes, 2017), sin mencionar que, actualmente son Gobierno. En ello nuestro sistema denota una franca vulneración al derecho de la identidad cultural protegido en toda la normativa vigente y desarrollado ampliamente por la doctrina y a nivel jurisprudencial por la Corte Internamericana de Derechos Humanos.

La utilización ancestral de las aguas en Chile, sea esta por asentamientos permanentes o transitorios, hace del recurso hídrico la base del desarrollo de diversas actividades productivas, como lo son la agricultura y la ganadería que, se continúan desarrollando, hasta el día de hoy, en territorios del desierto de Atacama como Bajo Soga, La Tirana, La Huayca y el Valle de Quisma, entre otros (Corporación nacional de desarrollo indígena, 2017). Para los pueblos indígenas andinos del norte de Chile, el agua como cualquier otro miembro de la comunidad andina, forma parte de una gran familia de seres y conforma parte integral de su identidad cultural. De esta forma, el ayllu es un concepto que, en sentido más amplio, se extiende más allá de los familiares humanos. Las rocas, los ríos, el sol, la luna, las plantas y los animales son también miembros del ayllu (Giovagnoli y Maloof, 2015). En esta línea los pueblos andinos 
del norte de Chile tienen un concepto diverso del agua, donde en términos de Van Kessel estaríamos frente a una tecnología tanto productiva como simbólica, en tanto todas sus actividades económicas productivas están acompañadas y enmarcadas en ceremonias religiosas que son parte de su saber producir (Basaure, 2015).

En esta lógica la comunidad andina vive de acuerdo al Suma Qamaña o vivir bien, concepto andino relacionado con la manera que los pueblos andinos entienden la vida (Ogawa, 2017). La comunidad andina es entonces una entidad compuesta por elementos de la naturaleza, incluida dentro de esta la persona que, se define siguiendo un largo proceso histórico, extendida en el tiempo hacia delante y hacia atrás, donde conoce sus orígenes y realiza su identidad en la vida. De acuerdo, entonces al concepto de comunidad andina de los pueblos indígenas del desierto de Atacama y en concordancia a la cosmovisión Aymara, la conexión con el agua es de carácter espiritual. El agua se une con los tres espacios espirituales, a saber, con el Arajpacha, Akapacha y Manquepacha. El Arajpacha es el mundo de arriba, donde habita el sol y la luna, que simboliza la luz y la vida. El Akapacha es el centro, y corresponde a los valles y quebradas. Por último, el Manquepacha, mundo de abajo, que simboliza la muerte y la oscuridad, allí donde se pierden las aguas y termina la vegetación (Valdivia, 2006).

En la cosmovisión andina el territorio involucra estos tres niveles, donde la legítimación de tenencia de tierras y aguas es una concepción unitaria de las actividades productivas y los aspectos sociales y culturales. En la cosmovisión andina no resulta natural ni entendible dividir el territorio, dejando al agua como un elemento separado de la tierra. De esta forma en la cultura andina del desierto de Atacama, se establecen sistemas de distribución del agua en turnos o mitas, valorando su uso eficiente y equitativo, una verdadera cultura del agua, donde en este mismo concepto concurren y se relacionan aspectos económicos y sociales. La identidad de los pueblos indígenas andinos se centró más en la dinámica étnica que en la ciudadanía, lo que permitió que se mantuvieran las estructuras comunitarias y los ritos y costumbres propios de la cultura Aymara ( Díaz, A.; Ruz, R.; Mondaca, C., 2004).

Esta cultura del agua andina del desierto de Atacama, fundamentalmente consagrada en sistemas de distribución del agua ha encontrado respaldo en la misma justicia chilena en el caso de Agua Mineral Chusmiza S.A.I.C. y la Comunidad Indígena Chusmiza Usmagama. Los poblados de Chusmiza y Usmagama, son parte de los antiguos poblados del desierto de Atacama que, formaban parte de la estructura incaica del Tawantinsuyu y sus antepasados y actuales integrantes han poseído y utilizado para uso agrícola, ganadero y doméstico las aguas de la vertiente denominada socavón de Chusmiza, de acuerdo a un mecanismo de distribución del agua entre los comuneros. La Corte de Apelaciones de Iquique, reconoció los derechos de agua provenientes del uso consuetudinario del recurso hídrico por parte de la comunidad indígena de Chusmiza Usmagama, sustentando su razonamiento en el derecho de propiedad, como derechos reconocidos de acuerdo a la Ley, a pesar de no haber estado escriturados al momento de la reclamación.

Dicho reconocimiento de los usos ancestrales del agua, por parte de los pueblos originarios andinos del desierto de Atacama, y sosteniendo el mismo criterio antes mencionado ante el máximo tribunal de los integrantes del Poder Judicial, como es la Excelentísima Corte Suprema de Chile se indicó que la eventual ausencia de inscripción de los derechos de aguas consuetudinarios no acarrea su inexistencia, sino solo la falta de su formalización registral y así, precisamente porque el derecho existe, se le reconoce por la ley (Corte Suprema, 2009). Este criterio resulta fundamental cuando tratamos sobre el actuar de un Estado en el establecimiento de políticas públicas y derecho uniforme a los pueblos originarios, puesto que entiende que el derecho de estos, proviene de un título sobre las aguas ancestralmente constituido, donde su inscripción, para las comunidades indígenas del norte de Chile constituye una mera formalidad. En este estado de las cosas es posible concluir que la territorialidad indígena debe ser entendida desde la perspectiva de los pueblos originarios y no desde la sociedad no indígena, tal como ocurrió con los usos consuetudinarios de los afluentes de agua en la comunidad indígena de Chusmiza Usmagama. Sobre este punto, el sistema de justicia internacional se ha pronunciado, explicando que, el derecho al territorio incluye el administrar, distribuir y controlar efectivamente este, de conformidad con su derecho consuetudinario y sistema de propiedad comunal, y sin 
perjuicio a otras comunidades indígenas y tribales (Corte Interamericana de Derechos Humanos, 2007). Es así como se reconoce, por parte del sistema internacional que, en los casos que involucren el interés sobre territorio de pueblos indígenas, se debe permitir su administración en conformidad a sus usos y costumbres ancestrales. La Corte Interamericana de Derechos Humanos llega incluso a indicar que, si se resolviera de otro modo equivaldría a sostener que, solo existe una forma de usar y disponer de los bienes, lo que a su vez significaría hacer ilusoria la protección del artículo 21 de la Convención para millones de personas (López, 2015). Para el sistema internacional es tan importante el reconocimiento de la cultura del agua de los pueblos originarios, así como del uso y posesión ancestral de ellos y del territorio que, el no reconocerlos pondría en jaque la supervivencia de los indígenas como pueblos organizados.

El derecho de uso consuetudinario del agua en el desierto de Atacama por parte de los pueblos andinos, se fundamenta en usos y prácticas, donde al Estado de Chile solo cabe el reconocimiento. En el caso particular del cierre de la cuenca hidrogeológica Pampa del Tamarugal del desierto de Atacama lleva a la exclusión de sus habitantes indígenas y eventualmente, les obligará a migrar al centro urbano y al abandono de su territorio ancestral. Cabe reflexionar en esta parte, si la actitud del Estado de Chile y la utilización del instrumento normativo estatal viene a reflejar el interés de un grupo cultural dominante por sobre los intereses de los pueblos indígenas y el cómo este control del Estado, subordina o incluso niega la cultura de los pueblos indígenas (Faundes, 2018).

\section{El Reconocimiento legal de los usos consuetudinarios indígenas de aguas y las políticas de los recursos hídricos en el desierto de Atacama}

Como ya hemos expresado hasta esta parte, resulta fundamental el ocuparnos de la actitud del Estado de Chile en el reconocimiento de los usos culturales del agua, sobre todo cuando se anticipa el efecto irracional del derecho en los casos que involucran a pueblos originarios. Para ello debemos considerar el marco legal que regula el agua y que, incluye a los demás los tratados internacionales ratificados por Chile. Entre tales figuran como más relevantes la ya mencionada Ley 19.253 que establece normas sobre protección, fomento y desarrollo de los indígenas, el decreto con fuerza de ley 1122 que fija el texto del Código de Aguas, así como el Convenio $\mathrm{N}^{\circ} 169$ de la Organización Internacional del Trabajo sobre pueblos indígenas y tribales.

Las aguas en Chile son bienes nacionales de uso público, de dominio de la Nación toda y su uso pertenece a todos los habitantes del país. Pero esto es solo para el caso del agua cuando esta se encuentra en su fuente natural. El artículo 5 del Código de Aguas, por su parte, otorga a los particulares el derecho de aprovechamiento de ellas. En la actualidad el modelo de derecho real de aprovechamiento puede transarse libremente en el mercado y es otorgado gratuitamente por el Estado, salvo el caso que el titular no haga uso de dicho derecho, caso en el que debe pagar una patente por el no uso. En opinión de Felipe Guerra este modelo ha supuesto un debilitamiento del poder regulatorio del Estado, lo que en conclusión vacía de contenido la condición del agua como bien nacional de uso público (Guerra, 2016).

El código de aguas además, no contempla regulación especial para los usos consuetudinarios de los pueblos indígenas en Chile, pudiéndose utilizar lo dispuesto en el artículo 2 transitorio, en cuanto otorga la posibilidad de regularizar los derechos de aprovechamiento inscritos que estén siendo utilizados por personas distintas de sus titulares a la fecha de entrar en vigencia el código de aguas, siempre que dichos usuarios hubieren cumplido 5 años de uso ininterrumpido.

Respecto a la protección de las aguas de las comunidades andinas en el desierto de Atacama, específicamente Aymara y Atacameños, nos encontramos ante una especial protección y serán considerados como bienes de propiedad y uso de la Comunidad Indígena establecida, pero manteniendo que solo se concederán en el caso de que no afecten los derechos que terceros hayan inscrito de conformidad al Código de Aguas. En el caso del cierre de la cuenca hidrogeológica del Tamarugal, además se restringió la constitución de nuevos derechos de aprovechamiento de aguas, sin distinguir si nos encontramos ante usos ancestrales de aguas por parte de pueblos originarios del desierto de Atacama. En la práctica entonces al no reconocer la costumbre jurídica indígena sobre el agua e imponer el cumplimiento de esta 
medida administrativa, se incumple el deber del Estado de Chile de reconocer los usos consuetudinarios sobre el agua en el desierto de Atacama y desconociendo, por tanto, la cultura ancestral del agua andina.

Es fundamental además considerar que, en virtud del inciso segundo del artículo 3 transitorio de la Ley 19.253 existe un deber de la Corporación Nacional de Desarrollo Indígena y de la misma Dirección General de Aguas de establecer un convenio para la protección, constitución y restablecimiento de los derechos de aguas de propiedad ancestral de las comunidades Aymara y Atacameña, de conformidad a lo dispuesto en el artículo 64 de dicha Ley. Esto debido a que esta norma tiene el carácter de especial justamente respecto al derecho al agua del pueblo Aymara y Atacameño.

Es así como, nuestro propio sistema jurídico interno permite la constitución de nuevos derechos de aprovechamiento de aguas, basados en el uso continuo de estas por 5 años en virtud del artículo 2 transitorio del Código de Aguas o en su caso alegar la titularidad del agua por parte de una comunidad indígena constituida en los términos del artículo 64 de la Ley 19.253. Y es aquí donde esta discusión normativa se vuelve especialmente llamativa, si internamente damos la posibilidad de regularizar y en su caso reconocer los usos ancestrales sobre el agua por parte de los pueblos indígenas, pero luego a través de un acto administrativo, tal como una resolución de un servicio público como es la Dirección General de Aguas, impedimos dicho ejercicio. En la práctica transgredimos la garantía establecida en el artículo 19 $\mathrm{N}^{\mathrm{o}} 2$ de la Constitución y afectamos directamente el principio de la seguridad jurídica del sistema de regularización de títulos de los derechos de aprovechamiento de aguas de los usuarios indígenas que estuvieren en la hipótesis del artículo 2 transitorio del Código de Aguas o del 64 de la Ley 19.253. A mayor abundamiento la propiedad de las comunidades indígenas, así reconocida por nuestro ordenamiento legal se encuentra además amparada por la garantía del artículo $19 \mathrm{~N}^{\circ} 24$ de la Constitución, al establecer este que se garantiza el derecho de propiedad de los derechos de los particulares sobre las aguas, reconocidos o constituidos en conformidad a la ley.

En el caso de los pueblos andinos del Tamarugal del desierto de Atacama, el cierre de la cuenca hidrogeológica afecta de forma continua a los pueblos indígenas, puesto que impide que opere el sistema de reconocimiento de los derechos de consuetudinario sobre el agua establecido en el Código de Aguas y en la Ley Indígena. Esto además se ve agravado por el especial estado de los pueblos indígenas, donde no hablamos de una mera expectativa de reconocimiento, sino más bien del deber de reconocimiento de los usos ancestrales del agua que obedecen a necesidades culturales, económicas y sociales de pueblos, de lo que se ha denominado cultura del agua andina.

\section{Desconocimiento de la posesión ancestral del agua de los pueblos andinos en el desierto de Atacama}

En la actualidad están en juego dos importantes principios, por una parte, el reconocimiento constitucional y legal de derechos de aguas preexistentes de carácter consuetudinario de los pueblos indígenas andinos del desierto de Atacama y, por otra, la protección del recurso hídrico disponible en la cuenca hidrogeológica de la pampa del Tamarugal. Entendiendo, de forma preliminar, la conexión espiritual del agua en la cosmovisión indígena andina, el cierre de la cuenca del Tamarugal, se puede al menos pensar que, esta decisión del Estado de Chile transgrede los artículos 8, 13, 14 y 15 del Convenio $\mathrm{N}^{\circ} 169$ de la OIT, e incluso se podría argumentar el artículo 16 , debido a que, no reconoce el derecho ancestral sobre las aguas y la especial conexión que los indígenas tienen con su territorio y viene a imposibilitar a las comunidades indígenas Aymara y Quechua ya determinadas, el subsistir en su territorio, lo que tendrá como consecuencia segura un éxodo a territorio urbano, con las consecuencias perversas que ello trae y la pérdida de nuestra historia intercultural. A lo que podemos agregar el aspecto geopolítico que implica un eventual despoblamiento de la cordillera debido a la migración a las ciudades de los indígenas andinos, situación que pudiere afectar al resguardo fronterizo y la seguridad nacional (Quiroz, D.; Díaz, A.; Galdames, L.; Ruz, R., 2011).

Por otro lado, referente a la necesidad de la declaración como área de restricción de la cuenca hidrogeológica del Tamarugal, la Dirección General de Aguas, fundamentó esta decisión en que, dicha medida era de carácter preventivo que 
se realizaba con base en estudios que demostraban que existía riesgo de grave disminución del determinado acuífero y no necesariamente frente a la constatación de un deterioro real en la actualidad. La resolución se sustentaba a su vez en los resultados del informe técnico de la Dirección General de Aguas No607 el que, determina la explotación sustentable era superada respecto de los usos existentes y previsibles de la demanda vigente al 30 de junio de 2009, produciéndose descensos sostenidos de niveles al grado de provocar reducciones superiores al $5 \%$ en el volumen embalsado en un plazo de 50 años (Dirección General de Aguas, 2009).

El cierre de la cuenca acuífera del Tamarugal en el desierto de Atacama tiene, entonces, impacto sobre los intereses de las comunidades originarias, pero además afecta directamente el principio de la seguridad jurídica, del sistema de regularización de títulos de los derechos de aprovechamiento de aguas de los usuarios que, a la entrada en vigencia del Código de Aguas hubieren cumplido cinco años de uso ininterrumpido de dichas aguas, en virtud del artículo 2 transitorio del Código de Aguas. El cierre, en consecuencia afecta de forma continua a las comunidades indígenas Aymara y Quechua antes mencionadas del desierto de Atacama, puesto que, impide que opere el sistema de reconocimiento de los derechos consuetudinarios sobre el agua, reconocidos a nivel legislativo en nuestro Código de Aguas y en la misma Ley Indígena $\mathrm{N}^{\circ} 19.253$, donde no hablamos de una mera expectativa de reconocimiento, sino más bien del deber de reconocer derechos de propiedad ancestrales que obedecen a necesidades culturales, económicas y sociales de los pueblos, cuya existencia es anterior a la configuración del Estado de Chile.

Esta forma de generar políticas públicas que, desestiman la cosmovisión indígena no es algo nuevo al Estado de Chile, especialmente en caso de los pueblos indígenas andinos del norte, donde bajo su administración hubo una suerte de acceso en cierta forma libre para personas de otras localidades, sin la defensa colectiva existente en el período previo a la anexión chilena, donde el uso y acceso a pastos, bofedales y tierras de pastoreo por personas ajenas al poblado era regulado por un grupo de comuneros y que se materializaba en oposiciones jurídicas a solicitudes "forasteras” (Ruz, R. \& Díaz, A., 2011). Esto sumado a la implementación de un sistema de registro de propiedad sobre la base del otorgamiento de títulos que certificaban el dominio del bien, definitivamente generan la desarticulación de las comunidades indígenas y la perdida de la noción de la propiedad colectiva.

Aparte de los perjuicios culturales, sociales y económicos a las comunidades indígenas derivados del cierre de la Pampa del Tamarugal, se suma la decisión estatal que busca conformar una comunidad de aguas subterráneas del sector hidrogeológico de Pampa del Tamarugal, donde sus socios se compondrían únicamente por aquellas comunidades, organizaciones e individuos que tengan derechos de aguas reconocidos y actualmente inscritos. Para configurar la comunidad, actualmente se encuentra en tramitación en el Juzgado de letras de Pozo Almonte la causa Rol $\mathrm{N}^{\circ}$ V-1597-2016, de 11 de mayo de 2016, que busca la aprobación de sus estatutos y elección del primer directorio provisorio. Procedimiento que, en la actualidad se encuentra entrampado, debido a la resistencia de las comunidades indígenas andinas del desierto de Atacama, que ha generado la suspensión de los comparendos atendiendo a sus acciones de protesta en las afueras del tribunal de Pozo Almonte y en la misma ciudad de Iquique.

Según indica Vergara, a la fecha de entrada en vigencia del Código de Aguas en 1981, una cantidad aproximada al $70 \%$ de los usos efectivos de aguas correspondía a usos consuetudinarios, los que carecían de títulos inscritos. La Dirección General de Aguas estima que de unos 350.000 derechos de aguas legítimos solamente alrededor de 70.000 están inscritos en el Registro de Propiedad de Derechos de Aguas del Conservador de Bienes Raíces (Vergara, 2018).

No debemos olvidar que la economía de los pueblos Aymara y Quechua del norte de Chile está basada en la agricultura y la ganadería, donde las especiales condiciones del clima y geografía de la zona permitieron que desde tiempos inmemoriales se aprendieran diversas técnicas de agricultura, principalmente el sistema de terrazas sembradas con diversos cultivos andinos; alfalfa, maíz, trigo, papa, ajo y orégano los que fueron introducidos a mediados del siglo XIX (Guzmán, 2008 en Castro, 2017) y cultivo en vegas. A este último sistema se le llama Mitas, que significa turno y consiste en un modelo de riego comunitario particular, este turno se ha concretado en un sistema de rotación 
en el cual los usuarios reciben el caudal total en un tiempo determinado (Gerbrandy Hoogendam, 1998 citado por Castro, 2017).

La situación de despojo de los pueblos indígenas andinos en Chile se suma que el actual proyecto de modificación del Código de Aguas dejará a sus usos consuetudinarios de aguas en una situación aún más compleja, debido a que se les quita a sus titulares el actual derecho a oponerse a solicitudes de terceros y sancionará con caducidad la falta de inscripción de estos usos costumbristas (Vergara, 2018).

Este trabajo se centra en el cierre de la cuenca hidrogeológica del Tamarugal, porque tiene en consideración que, esta decisión administrativa viene a empeorar la situación de despojo que viven los pueblos indígenas andinos en el desierto del Tamarugal. Se ha argumentado hasta aquí que, dicha situación se deriva de la imposición de una lógica antropocéntrica, esto es aún más evidente, cuando consideramos que, con fecha 11 de mayo de 2016 la Dirección General de Aguas inició un procedimiento judicial sobre constitución de una comunidad de aguas subterráneas del sector hidrogeológico Pampa del Tamarugal ante el juez competente, Juzgado de letras y Garantía de Pozo Almonte (Conadi, 2017). Se hace aún mas dramáticamente patente la diferencia de concepciones del mundo o cosmovisiones entre lo occidental y lo originario, que se halla desde la misma cosmovisión de los pueblos andinos.

\section{Conclusiones}

Es necesario repensar la relación que el Estado de Chile ha mantenido sistemáticamente con sus pueblos originarios. Como hemos desarrollado hasta aquí, estamos ante la tensión de dos intereses fundamentales, por una parte el reconocimiento de un sistema intercultural que incluye la visión, participación y consentimiento de los pueblos indígenas en las decisiones del Estado de Chile cuando les afecte directamente y por otro, el cuidado del agua como recurso escaso en el desierto más arido del mundo. En esa línea es atendible entonces el cierre de la cuenca hidrogeológica del Tamarugal, sin embargo, el criterio utilizado para equiparar a los pueblos Andinos con el resto de la comunidad chilena refleja un criterio de exclusión. No se satisface nuestro compromiso como Estado con la mera participación de grupos afectados en la decisión de estrategias nacionales de cuidado del agua, nuestro deber como Estado intercultural, que es parte del Convenio $\mathrm{N}^{\circ} 169$ de la OIT es a consultar en la búsqueda de la obtención del consentimiento de los pueblos indígenas.

Como ya hemos señalado en el trabajo, el no permitir nuevas inscripciones de usos de agua ni reconocer usos ancestrales de agua de los pueblos andinos, provocará un éxodo forzado de sus territorios tradicionales hacia la ciudad. Es así como la definición de una política del cuidado del agua por parte del Estado de Chile, sin el debido consentimiento de los usuarios ancestrales del agua, genera un daño irreparable a dichos pueblos del desierto de Atacama. Vale entonces considerar un cambio en la dinámica del Estado de Chile, llegando a comprender un verdadero deber de respeto respecto de los pueblos indígenas del norte del país, comprendiendo que la inclusión de la cosmovisión andina del cuidado del agua y la producción tradicionales solo vendrán a mejorar el cuidado de tan importante recurso.

Se comprende esta relación instaurada por el Estado de Chile como parte del efecto pernicioso de un sistema jurídico homogéneo e uniforme, que no reconoce su propia interculturalidad o más bien desconoce la riqueza de la cultura jurídica de los pueblos indígenas en Chile, sobre todo en materias de cuidado del agua. Se hace necesario superar este sistema y hacer un verdadero reconocimiento de la costumbre jurídica indígena.

Según hemos estudiado, el cierre de la cuenca hidrogeológica Pampa del Tamarugal en el desierto de Atacama no podría aplicarse a los pueblos andinos y correspondería al Estado el deber de reparación del daño causado. Deberían entonces reconocerse los usos consuetudinarios del agua de las comunidades indígenas afectadas en virtud de lo dispuesto en el artículo 64 de la Ley 19.253, así como también el artículo $2^{\circ}$ transitorio del Código de Aguas, teniendo en consideración la especialidad de dicha normativa para las comunidades indígenas Aymara, como medida de reparación y como forma de reconocimiento de la cosmovisión indígena andina y de la cultura del agua. Obligación por demás, consagrada en el inciso segundo del artículo $3^{\circ}$ transitorio de la Ley 19.253 que, establece el deber de la Corporación Nacional de Desarrollo Indígena y de la misma Dirección General de Aguas de establecer un convenio para la protección, constitución y restablecimiento de 
los derechos de aguas de propiedad ancestral de las comunidades Aymara y Atacameña.

Solo de este modo pasaremos de una política institucional que excluye a los pueblos indígenas a una verdaderamente intercultural que, por lo demás, vendría a reflejar a este verdadero Estado chileno, el que vivimos mas allá de los códigos y fuentes escritas del derecho.

\section{Referencias Citadas}

Aylwin, J; Meza-Lopehandia, M. y Yáñez, N.

2013 Los pueblos indígenas y el derecho. LOM Ediciones, Observatorio Ciudadano, Santiago, Chile.

Bassaure, $\mathrm{M}$.

2015 Población Aymara en los humedales de la comuna de Pica. Región de Tarapacá (tesis de pregrado) Universidad de Chile, Santiago, Chile.

Castro, M.; Bahamondes, M.; Albornoz, P.; Bassaure, M.;

Cayo, S.; Larama, S., e Hidalgo, R.

2017 El Derecho Consuetudinario en la gestión del riego en Chiapa. Las aguas del Tata Jachura. Disponible en https://doi.org/10.34720/42 $7-6 z 84$.

Centro de Estudios de Desarrollo y la Corporación Nacional de Desarrollo Indígena

2012 Agua, Poder y Conflicto Étnico. Recuperado de https://www.cepal.org/drni/proyectos/walir/doc/walir3. pdf

Comisión Interamericana de Derechos Humanos

2013 Informe $N^{\circ} 29 / 13$, petición admisibilidad Comunidad indígena Aymara de Chusmiza-Usmagama y sus miembros Chile. Recuperado de www.oas.org/es/cidh/ decisiones/2013/CHAD1288-06ES.doc.

Contesse, J.

2012 El Convenio 169 de la OIT y el Derecho chileno. Mecanismos y obstáculos para su implementación. Ediciones Universidad Diego Portales, Santiago, Chile.

Contraloría General de la República.

2014 Informe $N^{o} 1$ sobre estrategia nacional de recursos hídricos. Recuperado de http://www. ministeriodesarrollosocial.gob.cl/transparencia/ documentos/f40b68_Informe_CGR_N1-2014_Estrat_ Nac_Resos_H\%C3\%ADdricos_DGA.pdf.

Corporación Nacional de Desarrollo Indígena

2017 Informe presentado ante la Corte Suprema en causa rol $N^{o}$ 37933-2017, Challapa con Dirección de Aguas. Recuperado de https://oficinajudicialvirtual.pjud.cl/ causas/doc_suprema.php

Corporación Nacional de Desarrollo Indígena

2016 Informe Estatutos Comunidad de Aguas Subterráneas Sector Hidrogeológico de Aprovechamiento Común Pampa del Tamarugal.

Corte de Apelaciones de Iquique

2017 Challapa con Dirección General de Aguas. Causa Rol No534-2017.

Corte Suprema

2008 Comunidad indígena Aymara Chusmiza-Usmagama con Sociedad de Agua Mineral Chusmiza. Recurso 2840-2008.

Corte Suprema.

2011 Asociación Indígena de Pueblos Atacameños contra la Comisión Regional del Medio Ambiente de la región de Antofagasta. Recuperado de http://www. politicaspublicas.net/panel/jp/1473-2011-cortesuprema-snpedro.html.

Díaz, A.; Ruz, R.; Mondaca, C.

2004 "La administración chilena entre los aymaras: resistencia y conflicto en los Andes de Arica (1901-1926)". Anthropologica, v. $22 \mathrm{~N}^{\circ}$ 22, 2004, pp. 215 a 235.

Dirección General de Aguas

2009 Resolución $N^{o} 245$. Recuperado de https://www.leychile.cl/Navegar?idNorma $=1013874$.

Dirección General de Aguas

2013 Plan Maestro de Recursos Hídricos. Recuperado de http://documentos.dga.cl/ADM5481v2.pdf.

Dirección General de Aguas

2014 Investigación y análisis de los mecanismos de recarga de la Pampa del Tamarugal. Recuperado de http:// www.dga.cl/estudiospublicaciones/Series\%20documentales/S.I.T. $\% 20 \mathrm{~N} \% \mathrm{C} 2 \%$ B0\%203 41\%20Informe $\% 20$ Final.pdf

Faundes, J.

2018 "Derecho fundamental a la identidad de los pueblos indígenas: un nuevo paradigma en la defensa penal indígena en Chile frente al Estado de Derecho hegemónico", Izquierdas, 45, febrero 2019. Pp. 51-78.

Fuentes, C. y de Cea, M.

2017 "Reconocimiento débil: derechos de pueblos indígenas en Chile". Perfiles latinoamericanos, Vol. $25 \mathrm{~N}^{\mathrm{o}} 49$, México, ene./jun. 2017. 1-21.

Giovagnoli, N y Maloof, C. (eds.)

2015 “Escrituras y Culturas". Tinkuy, 22, pp. 119-120.

Guerra, F.

2016 "Resolución de disputas de los conflictos en toro al agua en Chile: Una respuesta institucional múltiple". Revista de Derecho Ambiental, IV, 6, 2016. pp. 205-223.

Huenchumilla, F. S.

2017 Boletín $N^{o}$ 11873-07, Proyecto de Reforma Constitucional para el reconocimiento de la plurinacionalidad y los derechos de los pueblos indígenas. Recuperado de http://www.labconstitucional.cl/wp-content/uploads/2018/07/Huenchumilla-mocion.pdf

Juzgado de Letras de Pozo Almonte.

2016 Procedimiento judicial sobre constitución de la comunidad de aguas subterráneas del Sector Hidrogeológico de aprovechamiento común Pampa del Tamarugal. Causa rol V- 15972016.

López, S.

2015 "La propiedad y su privación o restricción en la jurisprudencia de la Corte Interamericana”. Ius et Praxis, 21, 1, pp. 531-576.

Quiroz, D.; Díaz, A; Galdames, L; Ruz, R.

2011 "Campesinos andinos y políticas agrarias durante la Junta de Adelanto de Arica (Azapa, Lluta y la 
precordillera, 1959-1976)". Idesia, Volumen 29, N², Mayo-Agosto, 2011. pp. 157-168.

Namancura, D.; Pinto, J.; Pairican, E.; Loncon, E.; Cortés, L.; Provoste, Y.; Condori, P.; Hucke, E.; Lincanqueo, E.; Cuminao, C.; Calfio, M.; Huinao, G.; Loncon, L.

2016 Nueva Constitución y Pueblos Indígenas. Universidad Academia de Humanismo Cristiano. Editorial Pehuén.

Ogawa, A.

2017 El Suma Qamaña: La convivencia a la salud según la gente Aymara de Arica, Codpa y Putre. Recuperado de https://digitalcollections.sit.edu/isp.collection/2548.

Organización Internacional del Trabajo.

1989 Convenio $N^{o} 169$ de la OIT sobre Pueblos Indígenas $y$ Tribales. Recuperado de https://www.ilo.org/ wcmsp5/groups/public/americas/rlima/ publication/ wcms_345065.pdf.

Organización de Estados Americanos

2013 Informe 29/13 Petición admisibilidad comunidad indígena Aymara de Chusmiza Usmagama y sus miembros Chile. Recuperado de http://www.oas.org/en/.

Pelfini, A y Mena, R.

2017 "Oligarquización y Extractivismo. Cerrojos a la democratización de la política ambiental en Chile". Perfiles Latinoamericanos, vol. $25 \mathrm{~N}^{\circ} 49$, pp. 252- 276.

Pfeffer, E.

2016 "Los tratados internacionales sobre derechos humanos y su ubicación en el orden normativo interno". Ius et Praxis, 9, 1, pp. 229-254.

Ruz, R.

2005 "Estado, Tierra y Comunidad Andina. Algunas notas sobre la Constitución de la propiedad de la tierra en la precordillera chilena. Siglos XIX-XX". Werken, segundo semestre, número 007. Universidad Internacional SEK. Santiago, Chile. Pp. 151-164.

Ruz, R. y Díaz, A.

2011 "Estado chileno y comunidad indígena. Presión y conflicto sobre tierras de uso colectivo en el espacio precordillerano de Arica: Putre 1880-1935”. Estudios Atacameños, Arqueología y Antropología Surandinas $\mathrm{N}^{\circ}$ 42, 2011. Pp. 173-188.

Salgado, J y Gomiz, M.

2010 Convenio 169 de la OIT sobre Pueblos Indígenas. Su aplicación en el derecho interno argentino. Observatorio de Derechos Humanos de Pueblos Indígenas, Neuquén, Argentina.

Valdivia, M.

2006 Cosmovisión Aymara y su aplicación en un contexto sanitario del norte de Chile. Recuperado de http://www. ub.edu/fildt/revista/pdf/RByD7_ArtValdivia.pdf

Vergara, A.

2018 "Regularización de derechos consuetudinarios de aguas: crítica a la jurisprudencia vacilante de la Corte Suprema”. Revista Estudios Públicos, 151. Pp. 59-122.

Vergara, A.

1998 Bases y principios del Derecho de Aguas en especial de los usos consuetudinarios. Anuario Universidad de Antofagasta. $\mathrm{N}^{\circ} 4$, pp. 119-123.

Vergara, A.

1992 "Contribución a la historia del Derecho de Aguas, III: Fuentes y principios del Derecho de Aguas Indiano", Revista chilena del derecho, Vol. 19, № 2, pp. 311-322.

Yáñez, N.A y Molina, R. (ed.).

2011 Las aguas indígenas en Chile. Santiago, Chile. LOM. 